\title{
The effectiveness of forgiveness therapy for wives of alcoholics
}

\author{
Hee kyung Kim ${ }^{* 1}$, Kunsook Bernstein ${ }^{2}$ \\ ${ }^{1}$ Inha University, Incheon, South Korea \\ ${ }^{2}$ Hunter-Bellevue School of Nursing, Hunter College, City University of New York, New York, United States
}

Received: June 6, 2017

DOI: $10.5430 /$ jnep.v7n12p72
Accepted: July 23, 2017

URL: https://doi.org/10.5430/jnep.v7n12p72

\begin{abstract}
Purpose: The purpose of this study was to examine the effectiveness of forgiveness therapy for wives of alcoholics in South Korea suffering from emotional abuse by their spouses.

Methods: Non-randomized quasi-experimental research was conducted with 2-hour weekly forgiveness therapy sessions for 12 weeks, and pre-test, post-test, and a 12-week follow-up test. A total number of 28 subjects were divided into two groups: 15 in the experimental group and 13 in the control group. The data were analyzed by descriptive statistics, $t$-test, $\chi^{2}$ test, and repeated measure ANOVA, using SPSS 20.0.

Results: The experimental group showed a significantly higher score on the forgiveness scale than did the control group $(t=$ $0.312, p<.010)$ and the 12 -week follow-up test $(\mathrm{F}=4.43, p=.039)$. In the subcategories of the forgiveness scale, affect and cognition scores were significantly increased but there was no significant change on the behavior score.

Conclusions: These findings suggest that forgiveness therapy may be an effective intervention program to improve forgiveness for the emotionally abused wives of alcoholics.
\end{abstract}

Key Words: Alcoholics, Forgiveness, Spouses

\section{INTRODUCTION}

Alcohol use disorder is a major health problem in Korea. According to an epidemiological survey, lifetime prevalence of alcohol use disorder for Koreans ages 16 to 64 years is $13.4 \%$. The report also indicates that Korea has a significantly higher rate of alcohol use disorder than other countries, including China (5.7\%), France (5.7\%), and Nigeria (3.0\%). ${ }^{[1]}$ But alcoholism is not only a problem of the addicted individual, it is considered a familial disease. ${ }^{[2]}$ Studies report that disruption in families caused by alcoholism is a serious, complex, and pervasive societal problem. ${ }^{[3]}$ Alcoholism can lead to various physical, psychosocial, and emotional problems for family members. ${ }^{[3,4]}$ Wives of alcoholics, in particular, experience the most direct impact of their husbands' drinking problem, such as physical violence, ${ }^{[5,6]}$ poverty, and emotional problems, including anxiety, depression, guilt, frustration, and anger. ${ }^{[3,4,7]}$ Repeated physical and emotional abuse, inflicted by alcoholic husbands, eventually impacts the wives mentally, resulting in feelings of despair and hopelessness. ${ }^{[7,8]}$ These negative outcomes may last well beyond the abusive relationship. The negative impacts may stay with the wives throughout their lives, despite separation, divorce, or achievement of sobriety by the husband. ${ }^{[9]}$ Therefore, apart from the problems of alcoholic husbands, their wives may benefit from intervention for emotional and psychosocial distress. ${ }^{[10]}$

Forgiveness therapy (FT) has emerged as a new intervention dealing with marital and family problems. ${ }^{[9]}$ Since 1995 ,

*Correspondence: Hee kyung Kim; Email: heekyungkim77@gmail.com; Address: Inha University, Incheon, South Korea. 
its use in clinical practice and research has continuously increased in the fields of marriage and family therapy, couples therapy, counseling, and individual psychotherapy. ${ }^{[11]}$ Scientific, clinical, and popular interest in forgiveness as a key component of therapeutic modality has exploded in recent years. ${ }^{[12]}$ Empirical research on FT in the past two decades has created a greater awareness of forgiveness as a form of psychotherapy ${ }^{[13]}$ and has established a causal relationship between forgiving an injustice and both the amelioration of anxiety and depression as well as improvement in selfesteem. ${ }^{[14-17]}$ The fundamental concept of FT is based on a conflict resolution strategy, which is often used in marital and interpersonal relationship therapy. ${ }^{[18]}$

Baskin and Enright define forgiveness as "willfully giving-up of resentment in the face of another person's considerable injustice and responding with beneficence to the offender even though that offender has no right to the forgiver's moral goodness". ${ }^{[19]}$ Also, Lundahl et al. claim that true forgiveness is a healthy response that can provide hope and confidence for the victim by alleviating the burden of past emotional pain. ${ }^{[20]}$ Forgiveness interventions are designed to benefit not only the victim, but also the forgiver, as the concept is not dependent on the actions of others. Forgiveness interventions target the individual's ongoing resentment, which without treatment can often lead to depression, anxiety, and other negative psychological outcomes. ${ }^{[18]}$ Enright et al. claimed that forgiveness is a choice, one of many ways to cope with emotional pain, and that it is an active process that requires the victim to journey through multiple steps. ${ }^{[21]}$ Therefore, forgiveness interventions include the development of positive feelings and thoughts - or at least the absence of negative thoughts and feelings - toward the offender. ${ }^{[22]}$ They can help the victim to stop blaming the offender for the sequelae of the offense and focus on developing their own emotions and cognitions to diminish unhealthy behaviors. ${ }^{[20]}$

FT was chosen for this study as a therapeutic intervention for wives of alcoholics to integrate their past and present life experiences, and to find a new meaning in their painful experience through forgiveness. ${ }^{[9]}$ Forgiveness therapy has not been used with wives of alcoholics. So the purpose of this study was to evaluate the effects of FT for the emotionally abused wives of alcoholics.

\section{MethodS}

\subsection{Study design and sample}

A non-equivalent control group pre-test/post-test and followup test design was used. The pre-test was conducted before starting the FT; the post-test was given immediately following the last session; the follow-up test was given 12 weeks after the last session.

Published by Sciedu Press
Subjects were wives of alcoholics and were recruited from two alcohol counseling centers and three Al-Anon groups in South Korea. Flyers indicating the purpose of the study were used to advertise for and recruit participants. The following inclusion criteria were used: 1) age 19 years and older, 2) has been receiving counseling because of husband's alcoholism, 3) sufficient literacy to complete a self-report of the study.

Using the $\mathrm{G}^{*}$ power 3.1 program based on the study that examined the effectiveness of FT for the women suffering from their spouses' emotional abuse, ${ }^{[9]}$ the adequate sample size was 10 for each group, with one tailed two groups $t$-test, a significance level of .05 , power of .80 , and an effect size of 1.22. A total of 34 participants were recruited and participated: 17 in the experimental group and 17 in the control group. Two participants in the experimental group and four in the control group decided not to continue. Thus, out of the 34 initially enrolled participants, 28 completed the study: 15 in the experimental group, 13 in the control group. Thirteen participants in the experimental group and no participant in the control group completed the follow-up test.

\subsection{The intervention: FT program}

FT is an active coping intervention that helps participants to decrease negative emotions, such as anger, anxiety, and depression, and to increase positive emotions in the relationship between two people. ${ }^{[19,23]}$ Forgiveness, in other words, is a process, not a single event. According to Enright's FT process model, forgiveness changes the affect, cognition, and behavior on the offender. In this process model, forgiveness decreases the negative emotions and unhealthy behaviors, allowing the victim to stop blaming the offender. ${ }^{[20]}$

FT is based on the process model of forgiveness developed by Enright. ${ }^{[24]} \mathrm{Kim}^{[25]}$ modified FT to create an appropriate FT intervention for wives of alcoholics by adding the family genogram and "Trauma Egg" diagram developed by Dahlen et al. to promote forgiveness through active selfexpression. ${ }^{[26]} \mathrm{A}$ family genogram has been considered essential to treating alcoholism because it is considered to be a family disease, and its potential negative impact on the relationship among family members has been significant. ${ }^{[10]}$ The Trauma Egg diagram is a form of drawing to help the affected individual think symbolically about painful or difficult events in his or her life. An individual draws the shape of a large oval egg. Starting at the bottom of the egg with the earliest painful memory, the individual draws a small symbol for each event, separating each one by a small curve-like shell inside of the egg ${ }^{[26]}$ (see Figure 1).

Enright's original model consisted of 20 manualized steps involving the following four phases: 1) uncovering (negative 
feelings about the offense), 2) decision (to pursue forgiveness for a specific instance), 3) work (toward understanding the offending person), and 4) discovery (of unanticipated positive outcomes and empathy for the offending person). ${ }^{[18]}$ $\mathrm{Kim}^{[25]}$ modified Enright's FT to 12 steps (see Table 1) to be culturally sensitive and also to promote uniformity in the treatment among Korean participants. This protocol was structured to guide each treatment session as follows: 1) defining forgiveness (what it is and is not), 2) distinguishing between forgiveness and reconciliation, 3) examining psychological defenses, 4) understanding anger, 5) examining abuser-inculcated shame and self-blame, 6) understanding cognitive rehearsal, 7) committing to forgive, 8) grieving the pain and losses from the abuse, 9) reframing the former abusive partner, 10) exploring empathy and compassion, 11) practicing goodwill, 12) finding meaning in unjust suffering and considering a new purpose in life of helping others. Table 1 shows the detailed weekly session contents of the revised FT. Participants attend weekly 2-hour sessions in a group of three-to-five members for 12 weeks.

\subsection{Measurement}

\subsubsection{Socio-demographic inventory}

In addition to each participant's socio-demographic information, the husband's alcohol-related characteristics were collected, including the husband's history of hospitalization, if any, and the period of diagnoses of alcoholism. Each participant's stress due to the husband's alcohol problems was measured on a scale from 1 to 10 , with 10 being the highest. The stress scale was used only to assess the intensity of their stress level and not to measure FT's effectiveness on a participant's stress level before and after the intervention.

\subsubsection{Enright forgiveness inventory-Korea}

The Korean version of the Forgiveness Inventory ${ }^{[27]}$ was used for this study. The original version was first developed by Enright ${ }^{[21]}$ and translated into Korean by Kim; ${ }^{[28]}$ Park tested the validity of the Enright Forgiveness Inventory-Korea (EFI$\mathrm{K}) .{ }^{[27]}$ EFI-K is a 60 -item self-report measurement of interpersonal forgiveness with items equally divided into six subscales: Positive and Negative Affect, Positive and Negative Behavior, and Positive and Negative Cognition. The score ranges from 60 to 360 , with a high score representing a high forgiveness. In previous studies, internal consistency of above 0.90 , test-retest reliability of 0.67 to 0.91 , and validity have been documented. ${ }^{[29]}$ Park reported a total Cronbach's alpha of 0.99 and an internal consistency of above 0.96 in subscales. ${ }^{[27]}$ The total Cronbach alpha for this study at pretest $(\mathrm{N}=28)$ was 0.955 , and affect 0.925 , behavior 0.904 , and cognition 0.885 .

Table 1. Contents of forgiveness therapy

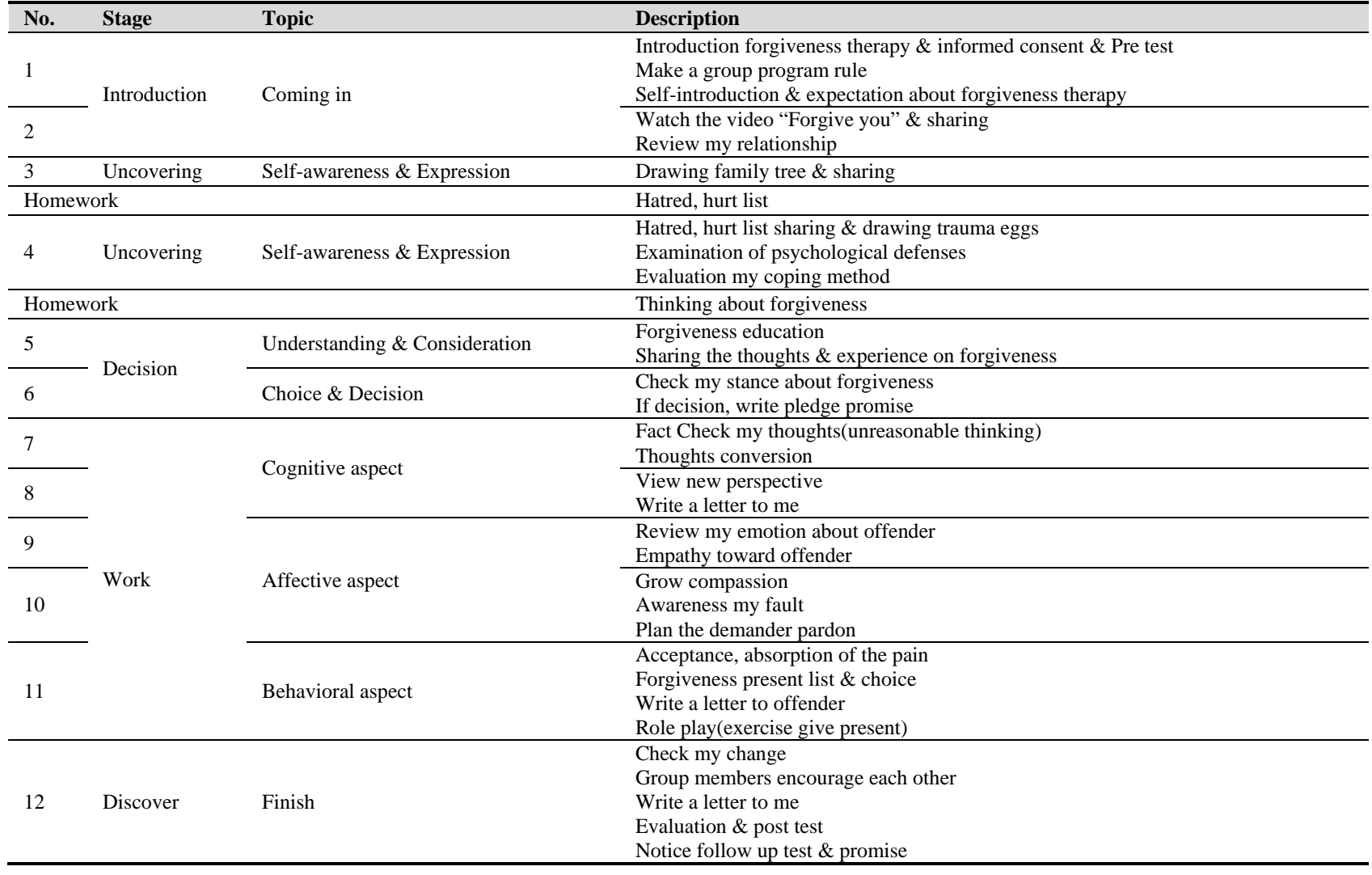




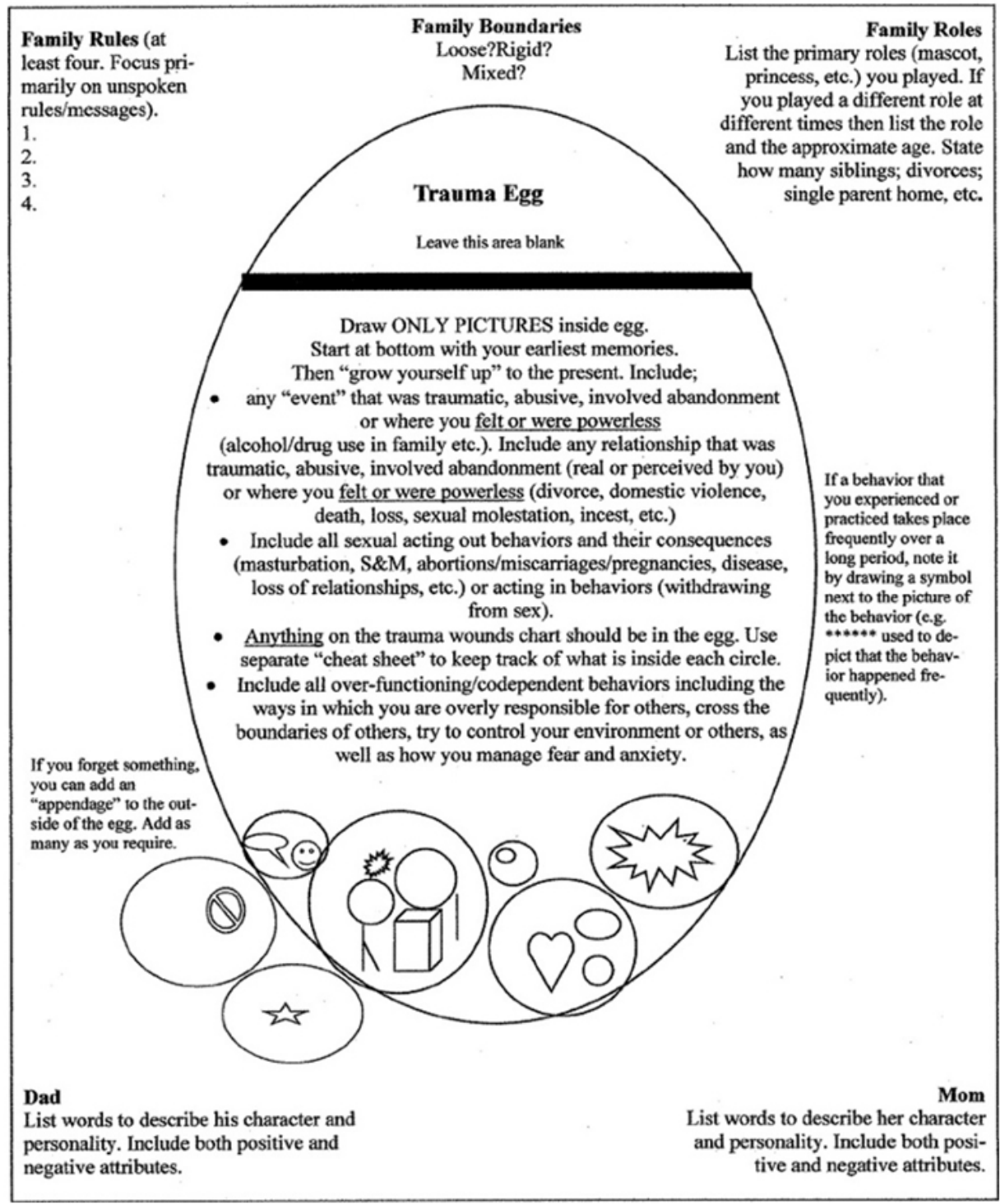

Figure 1. Sample of trauma egg ${ }^{[26,34,35]}$

\subsection{Procedure and data collection}

The researchers contacted a local community alcohol treatment center and self-help group organizations (i.e., Al-Anon) in South Korea, and met with its head to explain the study's purpose. The study was then approved by the university's institutional review board (IRB). With permission, the researchers posted the advertising flyer in the center's waiting area. Potential participants who expressed interest and who met the sampling criteria were recruited. The purpose of the study, study procedure, contents of FT, confidentiality, and the right to quit the study at any time without penalty were explained to all participants.

The 34 participants were assigned by preference to either the experimental group $(\mathrm{N}=17)$ or the control group ( $\mathrm{N}$ =17). Participants in the experimental group received 12 sessions of FT, and participants in the control group received the usual intervention (i.e., individual counseling and family therapy) available at the sites. Pre-test was given prior to start of the intervention and post-test was done immediately following the completion of the intervention. All participants completed the pre- and post- test using the EFI-K. A follow-up test was conducted 12 weeks after completion of the intervention. For security and confidentiality purposes, each FT session took place in a quiet and separate room in the designated community centers. The study was conducted between March of 2012 and December of 2013.

\subsection{Data analysis}

The collected data were analyzed using SPSS Statistics 20 for Windows. Descriptive statistics of frequency and percentage were performed to describe the demographic characteristics 
and baseline study variables of the experimental and control groups. Independent $t$-test and $\chi^{2}$ test were used for homogeneity and to identify any differences between the two groups. An independent t-test was used to measure the differences between forgiveness scores. Repeated Measure
ANOVA was used for the experimental participants' change from post-test to follow-up test in forgiveness scores. All reported $p$ values were two-sided, and the significance level of .05 was applied.

Table 2. Homogeneity of demographic Characteristics and study variables $(\mathrm{N}=28)$

\begin{tabular}{|c|c|c|c|c|c|c|}
\hline \multirow{2}{*}{ Variables } & \multirow{2}{*}{ Categories } & $\operatorname{Exp}^{*}(n=15)$ & Cont $^{* *}(n=13)$ & Total $(n=28)$ & \multirow{2}{*}{$\chi^{2} / \mathbf{t}$} & \multirow{2}{*}{$p$} \\
\hline & & \multicolumn{3}{|c|}{ n $(\%)$ or $\mathrm{M} \pm \mathrm{SD}$} & & \\
\hline \multirow{4}{*}{ Religion } & Christianity & $6(40.0)$ & $6(46.2)$ & $12(42.9)$ & \multirow{4}{*}{4.15} & \multirow{4}{*}{.246} \\
\hline & Buddhism & $0(0.0)$ & $1(7.7)$ & $1(3.6)$ & & \\
\hline & Catholic & $8(53.3)$ & $3(23.1)$ & $11(39.3)$ & & \\
\hline & None & $1(6.7)$ & $3(23.1)$ & $4(14.3)$ & & \\
\hline \multirow{4}{*}{ Marital status } & Married & $13(86.7)$ & 12 (92.3) & 25 (89.3) & \multirow{4}{*}{2.91} & \multirow{4}{*}{.405} \\
\hline & Divorced & $0(0.0)$ & $1(7.7)$ & $1(3.6)$ & & \\
\hline & Separated & $1(6.7)$ & $0(0.0)$ & $1(3.6)$ & & \\
\hline & Widowed & $1(6.7)$ & $0(0.0)$ & $1(3.6)$ & & \\
\hline \multirow{3}{*}{$\begin{array}{l}\text { Subjective } \\
\text { economic status }\end{array}$} & Moderate & $8(53.3)$ & $3(23.1)$ & $11(39.3)$ & \multirow{3}{*}{2.96} & \multirow{3}{*}{.227} \\
\hline & Slightly below & $4(26.7)$ & $7(53.8)$ & $11(39.3)$ & & \\
\hline & Poor & $3(20.0)$ & $3(23.1)$ & $6(21.4)$ & & \\
\hline \multirow{3}{*}{$\begin{array}{l}\text { Hospitalization of } \\
\text { Spouses }\end{array}$} & Yes & $9(60.0)$ & $10(76.9)$ & 19 (67.9) & \multirow{2}{*}{.914} & \multirow{2}{*}{.435} \\
\hline & None & $6(40.0)$ & $3(23.1)$ & $9(32.1)$ & & \\
\hline & Number of hospitalization & $3.60 \pm 6.40$ & $7.31 \pm 7.95$ & $5.32 \pm 7.27$ & -1.37 & .183 \\
\hline \multicolumn{2}{|c|}{ Diagnostic period (yr) } & $11.08 \pm 9.56$ & $9.04 \pm 8.19$ & $10.52 \pm 8.90$ & 0.814 & .423 \\
\hline \multicolumn{2}{|l|}{ Age (yr) } & $54.33 \pm 8.52$ & $51.62 \pm 10.60$ & $53.07 \pm 9.45$ & 0.75 & .458 \\
\hline \multicolumn{2}{|c|}{ Number of family member in household } & $2.87 \pm 0.83$ & $3.23 \pm 1.09$ & $3.04 \pm 9.45$ & -1.00 & .327 \\
\hline \multirow{2}{*}{ Attendance Al-anoı } & Attendance & $13(86.7)$ & $9(69.2)$ & $22(78.6)$ & \multirow{2}{*}{1.26} & \multirow{2}{*}{.372} \\
\hline & No & $2(13.3)$ & $4(30.8)$ & $6(21.4)$ & & \\
\hline \multicolumn{2}{|c|}{ Attendance period of Al-anon (yr.) } & $3.60 \pm 2.97$ & $3.73 \pm 6.32$ & $3.66 \pm 4.73$ & -0.72 & .943 \\
\hline \multicolumn{2}{|c|}{ Stress due to Spouse's alcohol problems } & $7.33 \pm 2.41$ & $6.08 \pm 2.72$ & $6.75 \pm 2.59$ & 1.30 & .206 \\
\hline \multicolumn{2}{|l|}{ EFI-K } & $160.93 \pm 45.34$ & $193.38 \pm 39.36$ & $176.00 \pm 45.01$ & -2.006 & .055 \\
\hline \multicolumn{2}{|l|}{ Affect } & $43.20 \pm 21.05$ & $54.46 \pm 12.98$ & $48.43 \pm 18.36$ & -1.671 & .107 \\
\hline \multicolumn{2}{|l|}{ Cognition } & $62.40 \pm 13.89$ & $73.00 \pm 16.77$ & $67.32 \pm 15.94$ & -1.830 & .079 \\
\hline \multicolumn{2}{|l|}{ Behavior } & $55.33 \pm 17.23$ & $65.15 \pm 19.65$ & $59.89 \pm 18.72$ & -1.410 & .170 \\
\hline
\end{tabular}

Note. Exp* $^{*}$ Experimental group; Cont** = Control group.

\section{RESULTS}

\subsection{Demographic characteristics of the participants and homogeneity in the two groups}

The demographic characteristics and homogeneity of variables are shown in Table 2. The mean age of the participants was $53.07(\mathrm{SD}=9.45)$ years old, and more than one-third were Christians. Most were presently married (89.3\%), and $60.0 \%$ of the experimental group and $76.9 \%$ of the control group had husbands with a history of alcohol abuse related hospitalizations. The mean period of husbands being diagnosed with alcoholism was $10.52(\mathrm{SD}=8.90)$ years, and par- ticipants reported a stress scale of $6.75(\mathrm{SD}=2.59)$ out of 10 due to the husband's alcohol problems; $78.6 \%$ of the participants attended Al-Anon, for an average of $3.66(\mathrm{SD}=4.73)$ years. In a homogeneity analysis, no significant intergroup difference was found in any demographic characteristics, and study variables (forgiveness) were also homogenous.

\subsection{Effectiveness of the forgiveness therapy on the study variables}

The results of an independent $t$-test analysis regarding differences between pre-test and post-test are shown in Table 3. There was a statistically significant difference in forgiveness 
score $(t=0.312, p<.010)$ between the experimental and forgiveness, affect and cognition scores in the experimenthe control group; the forgiveness score of the experimental tal group significantly increased even though no significant group significantly increased following the FT compared to changes in the behavior score were noted. that of the control group. Additionally, in a subcategory of

Table 3. Effects of Forgiveness therapy $(\mathrm{N}=28)$

\begin{tabular}{|c|c|c|c|c|c|c|}
\hline Variables & Group & $\begin{array}{l}\text { Pre test } \\
M \pm \text { SD }\end{array}$ & $\begin{array}{l}\text { Post test } \\
M \pm \text { SD }\end{array}$ & $\begin{array}{l}\text { Difference } \\
M \pm \text { SD }\end{array}$ & $t$ & $p$ \\
\hline \multirow{2}{*}{$\begin{array}{l}\text { Enright Forgiveness Inventory } \\
\text {-Korea }\end{array}$} & Exp. $(n=15)$ & $160.93 \pm 15.14$ & $204.33 \pm 55.45$ & $43.40 \pm 45.36$ & \multirow{2}{*}{0.312} & \multirow{2}{*}{.010} \\
\hline & Cont. $(n=13)$ & $193.38 \pm 39.36$ & $193.46 \pm 32.58$ & $0.08 \pm 36.23$ & & \\
\hline \multirow{2}{*}{ Affect } & Exp. $(n=15)$ & $43.20 \pm 21.05$ & $63.53 \pm 20.46$ & $20.33 \pm 19.16$ & \multirow{2}{*}{0.055} & \multirow{2}{*}{.012} \\
\hline & Cont. $(n=13)$ & $54.46 \pm 12.98$ & $58.46 \pm 15.91$ & $4.00 \pm 11.25$ & & \\
\hline \multirow{2}{*}{ Positive affect } & Exp. $(n=15)$ & $26.33 \pm 13.34$ & $32.00 \pm 11.38$ & $5.67 \pm 12.61$ & \multirow{2}{*}{1.222} & \multirow{2}{*}{.233} \\
\hline & Cont. $(n=13)$ & $28.31 \pm 8.90$ & $29.08 \pm 7.81$ & $0.77 \pm 7.53$ & & \\
\hline \multirow{2}{*}{ Negative affect } & Exp. $(n=15)$ & $16.87 \pm 9.98$ & $31.53 \pm 12.25$ & $14.67 \pm 12.23$ & \multirow{2}{*}{2.931} & \multirow{2}{*}{.007} \\
\hline & Cont. $(\mathrm{n}=13)$ & $26.15 \pm 8.67$ & $29.38 \pm 9.12$ & $3.23 \pm 7.42$ & & \\
\hline \multirow{2}{*}{ Cognition } & Exp. $(n=15)$ & $62.40 \pm 13.89$ & $72.00 \pm 17.74$ & $9.60 \pm 12.96$ & \multirow{2}{*}{0.742} & \multirow{2}{*}{.03} \\
\hline & Cont. $(\mathrm{n}=13)$ & $73.00 \pm 16.77$ & $71.08 \pm 11.94$ & $-1.92 \pm 14.22$ & & \\
\hline \multirow{2}{*}{ Positive Cognition } & Exp. $(\mathrm{n}=15)$ & $33.67 \pm 8.63$ & $36.87 \pm 8.75$ & $3.20 \pm 6.24$ & \multirow{2}{*}{0.749} & \multirow{2}{*}{.212} \\
\hline & Cont. $(\mathrm{n}=13)$ & $35.85 \pm 8.90$ & $35.69 \pm 6.63$ & $-0.15 \pm 7.64$ & & \\
\hline \multirow{2}{*}{ Negative Cognition } & Exp. $(n=15)$ & $28.73 \pm 7.72$ & $35.13 \pm 10.04$ & $6.40 \pm 8.79$ & \multirow{2}{*}{0.789} & \multirow{2}{*}{.032} \\
\hline & Cont. $(n=13)$ & $37.15 \pm 12.48$ & $35.38 \pm 9.57$ & $-1.77 \pm 10.34$ & & \\
\hline \multirow{2}{*}{ Behavior } & Exp. $(n=15)$ & $55.33 \pm 17.23$ & $68.80 \pm 18.94$ & $13.47 \pm 19.30$ & \multirow{2}{*}{0.668} & \multirow{2}{*}{.082} \\
\hline & Cont. $(n=13)$ & $65.15 \pm 19.65$ & $63.92 \pm 11.15$ & $-1.23 \pm 23.65$ & & \\
\hline \multirow{2}{*}{ Positive Behavior } & Exp. $(n=15)$ & $29.40 \pm 10.25$ & $33.40 \pm 11.98$ & $4.00 \pm 11.19$ & \multirow{2}{*}{1.145} & \multirow{2}{*}{.263} \\
\hline & Cont. $(\mathrm{n}=13)$ & $33.00 \pm 10.392$ & $31.92 \pm 7.37$ & $-1.08 \pm 12.27$ & & \\
\hline \multirow{2}{*}{ Negative Behavior } & Exp. $(n=15)$ & $25.93 \pm 11.33$ & $35.40 \pm 9.41$ & $9.47 \pm 12.10$ & \multirow{2}{*}{2.253} & \multirow{2}{*}{.033} \\
\hline & Cont. $(\mathrm{n}=13)$ & $32.92 \pm 10.69$ & $32.00 \pm 7.76$ & $-0.92 \pm 12.25$ & & \\
\hline
\end{tabular}

Note. $p \leq .05$, Difference $=$ Post-Pre; Exp. $=$ Experimental group; Cont. $=$ Control group.

Table 4. Follow up test of experimental group (Persistence effect verification) $(\mathrm{N}=13)$

\begin{tabular}{|c|c|c|c|c|c|}
\hline Variables & $\begin{array}{l}\text { Pre test } \\
M \pm S D\end{array}$ & $\begin{array}{l}\text { Post test } \\
M \pm \text { SD }\end{array}$ & $\begin{array}{l}\text { Follow up test } \\
M \pm S D\end{array}$ & $\mathbf{F}$ & $p$ \\
\hline Enright Forgiveness Inventory & $165.23 \pm 46.31$ & $200.69 \pm 57.52$ & $192.38 \pm 49.89$ & 4.43 & .039 \\
\hline Affect & $46.15 \pm 20.97$ & $61.85 \pm 20.86$ & $58.46 \pm 19.68$ & 6.18 & .016 \\
\hline Positive affect & $28.15 \pm 13.40$ & $30.85 \pm 11.82$ & $31.62 \pm 10.96$ & 1.01 & .394 \\
\hline Negative affect & $18.00 \pm 10.18$ & $31.00 \pm 12.20$ & $26.85 \pm 11.77$ & 7.44 & .009 \\
\hline Cognition & $64.85 \pm 13.28$ & $71.85 \pm 19.00$ & $67.85 \pm 17.54$ & 3.47 & .068 \\
\hline Positive Cognition & $35.00 \pm 8.48$ & $36.77 \pm 9.18$ & $37.69 \pm 8.43$ & 0.93 & .424 \\
\hline Negative Cognition & $29.85 \pm 7.65$ & $35.08 \pm 10.84$ & $30.15 \pm 10.85$ & 5.40 & .023 \\
\hline Behavior & $54.23 \pm 16.52$ & $67.00 \pm 19.14$ & $66.08 \pm 16.36$ & 2.32 & .145 \\
\hline Positive Behavior & $29.54 \pm 10.64$ & $32.23 \pm 12.26$ & $31.85 \pm 11.63$ & 0.44 & .656 \\
\hline Negative Behavior & $24.69 \pm 10.64$ & $34.77 \pm 9.65$ & $34.23 \pm 8.70$ & 3.72 & .058 \\
\hline
\end{tabular}

Note. $p \leq .05$

\subsection{Persistence effect verification}

The mean change scores of the experimental group were examined in the results of the follow-up test. Thirteen participants in the experimental group completed this test, and the Published by Sciedu Press results are shown in Table 4. In this group, the follow-up test showed a statistically significant increase in forgiveness $(\mathrm{F}=$ $4.43, p=.039)$. In the forgiveness subcategory, only affect significantly increased $(\mathrm{F}=6.18, p=.016)$; the difference 
in behavior and cognition was not significant $(\mathrm{F}=3.47, p=$ $.068, \mathrm{~F}=2.32, p=.145)$. There was no data on the follow-up test for the control group, as none of the participants were reachable for it.

\section{DisCussion}

This study focused on evaluating the effectiveness of FT on the wives of alcoholics who were suffering from their husband's alcoholism. In this study, the demographic characteristics of middle age (mean age of 53 years) and married $(89.3 \%)$ Korean women were similar to those in the study by Chio \& Oh (2007) who explored the forgiveness ability of middle-age married women. Chio \& Oh found that Korean women who experienced difficulty forgiving yet stayed in the marriage did so to avoid guilt and because it is viewed as culturally unacceptable by Korean society to leave one's husband. ${ }^{[30]}$ In the current study, the majority of participants' husbands were diagnosed with alcoholism more than 10 years earlier, yet these women stayed with them. The majority of participants (78.6\%) sought support by attending Al-Anon family groups, which are designed to offer strength and hope for friends and families of problem drinkers.

The outcomes of the effectiveness of FT in this study are supported by other studies. ${ }^{[9,15,31]}$ In this study, overall positive changes of forgiveness scores were statistically significant; however, the sub-categorical changes, such as affect, cognition, and behavior, were different from other studies. ${ }^{[9,15]}$ Hebl and Enright's 8-week FT with elderly females who had a history of emotional trauma reported that it improved their negative feelings and thoughts toward the offender, as evidenced by significant positive changes in affect, cognition, and behavior, and indicated that the FT intervention was able to successfully bring the elderly women toward forgiving their offenders. ${ }^{[31]}$ Also, the study of Freedman \& Enright with incest survivors reported significant changes in all subcategories. ${ }^{[16]}$

Here, however, the subcategories of forgiveness scores, affect and cognition, significantly increased, but the behavior score showed no significant changes. This may be related to a culturally unique symbolic emotional expression of Korean women called "Han", which represents a syndrome characterized by internalized regret or resentment with few outlets to externalize those emotions behaviorally. ${ }^{[32]}$ Wives of alcoholics in Korea may have experienced "Han", living with resentment and holding their negative emotions back to keep the family together and sacrificing themselves for the greater good. Therefore, this "Han" culture may have negatively influenced the changes in behavior scores of forgiveness, unlike other FT studies which showed improvement in all three subcategories of the forgiveness score. No significant change in the behavior scores of the Korean women in this study may indicate that action-oriented (behavior) changes did not happen because culturally a Korean woman may be able to feel (emotion) and think (cognition). However, Korean women may be unable to externalize those feelings and thoughts into action because that behavior is unacceptable in Korean culture.

Few studies have utilized FT as a therapeutic option for treating wives of alcoholics. FT may be culturally suitable for Korean women suffering from emotional abuse inflicted by their alcoholic husbands since forgiveness is considered as an option. There are several options can be considered such as making the decision to forgive, grieving the pain from the injustice, reframing the wrongdoer, relinquishing resentment, developing goodwill, finding meaning in the unjust suffering, and discovering psychological release and a new purpose in life. ${ }^{[9]}$ Enright found that when people went through the stages of the forgiveness process, they could ultimately find a purpose of life. ${ }^{[2]}$ This is similar to Kim \& Lee's analysis of the experience of FT by Korean wives of alcoholics, in which the last stage of the recovery process is growth. ${ }^{[10]}$ Kim reported that FT provided new meaning to individuals' lives because people tend to forgive the perpetrator when they matured. ${ }^{[25]}$ Reed \& Enright described this as a therapeutic aspect of forgiveness, and FT has a distinct advantage in this aspect of recovery. ${ }^{[9]} \mathrm{Kim} \&$ Lee's study indicated that the FT significantly improved resilience, self-esteem, and spirituality of the wives of the alcoholic. They also reported that resilience was an important factor in its long-term effect on maintaining the acquired positive impact on the self-esteem and spirituality from the FT. ${ }^{[10]}$

Another noteworthy finding was the lasting effectiveness of FT in the 12-week follow-up, which is supported by several other studies. Reed and Enright reported an overall psychological improvement following FT, such as in anxiety, depression, and posttraumatic stress symptoms, and forgiveness; those gains were maintained at follow-up, but did not specify how long after the original study the followup occurred. ${ }^{[9]}$ Wade et al. conducted a meta-analysis of FT studies and reported that the follow-up analyses suggested a pattern of strong improvement in the FT group post-intervention followed by maintenance of gains at the follow-up assessment. ${ }^{[33]}$

Our study has several limitations. First, this study did not completely exclude the Hawthorne effect from the convenience sampling of willing participants; bias associated with unblended raters may also be present. Additionally, participants were allowed to self-select into a group thus creating the potential for bias. Since the potential research subjects 
volunteer to take part in the survey, there is likely to be a degree of self-selection bias. For example, the decision to participate in the study may reflect some inherent bias in the characteristics/traits of the participants (e.g., a subject wanting to give an opinion). Also, this can either lead to the sample not being representative of the population being studied, or exaggerating some particular finding from the study. Despite the potential disadvantages of self-selection sampling, it is a popular sampling technique in many areas of science that require human subjects.

Therefore, the outcome for this study cannot be generalized to the entire population of wives of alcoholics. Second, a time-series design is needed to get a power of intervention, as this study had no follow-up test for the control group and therefore no comparison can be made between it and the experimental group. Third, since many of the participants reported religious affiliations this may also contribute to bias There are limited studies in comparison between forgiveness within religious practice and forgiveness therapy as a form of psycho-therapeutic practice. However, the healing aspect of forgiveness has been supported by religious for centuries. ${ }^{[36]}$
McCullough \& Worthington (1999) reported positive association of forgiveness with religiousness, ${ }^{[37]}$ and the role of religion in forgiveness was reported to be strategized by many people who has a religion. ${ }^{[38]}$ Lastly, the sample size is too small to generalize the results. Despite its limitation, though, the outcomes of this study may contribute to further development of culturally specific FT in treating emotionally abused wives of alcoholics in various mental health settings.

\section{Conclusion}

The outcomes of this study demonstrate the cultural specificity of the forgiveness process looking at Korean wives of alcoholics who were suffering from emotional abuse inflicted by their husbands' drinking problems. This preliminary study may provide a fundamental understanding of FT as a culturally sensitive clinical intervention to enhance emotional stability and inner healing of the emotionally abused wives of alcoholics.

\section{Conflicts of InTERest Disclosure}

The authors declare that there is no conflict of interest.

\section{REFERENCES}

[1] Statistics Korea. 2011 The epidemiological survey of Mental disorder in Korea [Online]. 2012. Available from: http://www.index.go .kr/potal/main/EachDtlPageDetail.do?idx_cd=1441 [Accessed: 4th May 2016].

[2] Peled E, Sacks I. The Self-Perception of Women Who Live with an Alcoholic Partner: Dialoging with Deviance, Strength, and Self-Fulfillment. Family Relations. 2008; 57(3): 390-403. https : //doi.org/10.1111/j.1741-3729.2008.00508.x

[3] Ramaya K, Paul L. Psychosocial problems of wives of alcoholics. Asian Journal Nursing Education and Research. 2013; 3(1): 29-30.

[4] Cho SH. Effects of logo-autobiography program on meaning in life and mental health in the wives of alcoholics. Asian Nursing Research. 2008; 2(2): 129-139. https://doi.org/10.1016/S197 6-1317 (08)60036-5

[5] Cho MS. A study on the influence of alcoholism of domestic violence offender to wife battering. Journal of Korean Alcohol Science. 2003; 3(1): 102-110.

[6] Kahler CW, McCrady BS, Epstein EE. Sources of distress among women in treatment with their alcoholic partners. Journal of Substance Abuse Treatment. 2003; 24: 257-265. http://doi .org/10 .1016/S07405472(03)00033-3

[7] Lee KW. The processes of life experiences that wives of alcoholic husbands have. Journal of Korean Academy Psychiatric Mental Health Nursing. 2001; 10(3): 406-420.

[8] Kang ES. A qualitative study on the experiences of alcoholics' wives. Korean Nursing Science. 1995; 7: 39-63.

[9] Reed GL, Enright RD. The effects of forgiveness therapy on depression, anxiety, and posttraumatic stress for women after spousal emotional abuse. Journal of Consulting and Clinical Psychology.
2006; 74(5): 920-929. http://doi.org/10.1037/0022-006X. 74.5 .920

[10] Kim HK, Lee MH. Effectiveness of forgiveness therapy on resilience, self-esteem, and spirituality of wives of alcoholics. Journal of Korean Academy of Nursing. 2014; 44(3): 237-247. http: //doi.org/10.4040/jkan.2014.44.3.237

[11] Walton E. Therapeutic forgiveness: Developing a model for empowering victims of sexual abuse. Clinical Social Work Journal. 2005; 33: 193-207. http://doi.org/10.1007/s10615-005-3532-1

[12] Harris AH, Luskin FM, Norman SS, et al. Effects of a group forgiveness intervention on forgiveness, perceived stress, and traitanger. Journal of Clinical Psychology. 2006; 62(6): 715-733. http: //doi.org/10.1002/jclp. 20264

[13] Rainey CA, Readdick CA, Thyer BA. Forgiveness-based group therapy: a meta-analysis of outcome studies published from 1993-2006. Best Practices in Mental Health. 2012; 8(1): 29-51.

[14] Al-Mabuk RH, Enright RD, Cardis PA. Forgiveness education with parentally love-deprived late adolescents. Journal of Moral Education. 1995; 24(4): 427-444. http://doi.org/10.1080/030572 495024045

[15] Coyle CT, Enright RD. Forgiveness intervention with postabortion men. Journal of Consulting and Clinical Psychology. 1997; 65(6): 1042-1046. http://doi.org/10.1037/0022-006X.65.6.1042

[16] Freedman SR, Enright RD. Forgiveness as an intervention goal with incest survivors. Journal of Consulting and Clinical Psychology. 1996; 64(5): 983-992. http://dx.doi.org/10.1037/0022-006 $\mathrm{X} .64 .5 .983$

[17] Lin WF, Enright RD, Mack D, et al. Effects of forgiveness therapy on anger, mood, and vulnerability to substance use among inpatient substance-dependent clients. Journal of Consulting and 
Clinical Psychology. 2004; 72(6): 1114-1121. PMid:15612857 http://doi.org/10.1037/0022006X.72.6.1114

[18] Enright RD, Fitzgibbons RP. Helping clients forgive: An empirical guide for resolving anger and restoring hope. Washington D.C.: American Psychological Association; 2000. 376p. https: //doi.org/10.1037/10381-000

[19] Baskin TW, Enright RD. Intervention studies on forgiveness: A metaanalysis. Journal of Counseling and Development. 2004; 82: 79-90. https://doi.org/10.1002/j.1556-6678.2004.tb00288.x

[20] Lundahl BW, Taylor MJ, Stevenson R, et al. Process-based forgiveness interventions: A meta-analytic review. Research on Social Work Practice. 2008; 18(5): 465-478. http://doi .org/10.1177/1049 731507313979

[21] Enright RD. Human Development Study Group. The moral development of forgiveness.Hillsdale, NJ.: Lawrence Erlbaum Associates 1991. 123p. (Kurtines WM, Gewirtz JL, editors. Handbook of moral behavior and development Vol. 1).

[22] Exline JJ, Worthington Jr EL, Hill P, et al. Forgiveness and justice: A research agenda for social and personality psychology. Personality and Social Psychology Review. 2003; 7(4): 337-348. http://doi.org/10.1207/S15327957PSPR0704_06

[23] Wade NG, Hoyt WT, Kidwell JEM, et al. Efficacy of psychotherapeutic interventions to promote forgiveness: a meta-analysis. Journal of Consulting and Clinical Psychology. 2014; 82(1): 154-170. http://doi.org/10.1037/a0035268

[24] Enright RD. Forgiveness is a choice: A step-by-step process for resolving anger and restoring hope. Washington, DC: American Psychological Association; 2001. 299p.

[25] Kim KS. The development and the effects of program for forgiveness. Korea Journal of Youth Counseling. 2002; 10(1): 165-191.

[26] Dahlen U, Colpitts D, Green C. The trauma egg as an intervention with the spouses of sexually addicted men. Sexual Addiction \& Compulsivity. 2008; 15(4): 346-354. http://doi .org/10.1080/1072 0160802516336

[27] Park JH. A review of forgiveness psychological theory and education program. The Korean Journal of Human Development. 2006; 13(1): 117-134.
[28] Kim KS. Development of education program for forgiveness [dissertation]. [Seoul]: Seoul University; 1999. 257p.

[29] Subkoviak MJ, Enright RD, Wu CR, et al. Measuring interpersonal forgiveness in late adolescence and middle adulthood. Journal of Adolescence. 1995; 18: 641-655. http://doi.org/10.1006/ja do.1995.1045

[30] Choi MO, Oh YJ. Exploration of forgiveness ability in middle-aged married women. Family and Environment Research. 2007; 45(10): 113-126.

[31] Hebl JH, Enright RD. Forgiveness as a psychotherapeutic goal with elderly females. Psychotherapy: Theory, Research, Practice, Training. 1993; 30(4): 658-667. https://doi.org/10.1037/0033-3204. 30.4 .658

[32] Chang WS. The effect of the group forgiveness program on anger, anxiety and depression for female elders. Journal of the Korean Gerontological Society. 2010; 30(1): 109-126.

[33] Wade NG, Worthington Jr EL, Meyer JE. But do they work? A meta analysis of group interventions to promote forgiveness. In E. L. Worthington, Jr. (Ed.), Handbook of forgiveness. New York, NY: Brunner/Routledge. 2005.

[34] Murray M. Prisoner of another war: A remarkable journey of healing from childhood trauma. CA: PageMill Press; 1991. 256p.

[35] Carnes PJ. The betrayal bond: Breaking free of exploitive relationships. FL: Health Communications Inc.; 1997. 249p.

[36] Brush BL, McGee EM, Cavanagh B, et al. Forgiveness: A concept analysis. Journal of Holistic Nursing. 2001; 19(1): 27-41. http://doi.org/10.1177/089801010101900104

[37] McCullough ME, Worthington Jr EL. Religion and the forgiving personality. Journal of personality. 1999; 67(6): 1141-1164. PMid:10637990 https ://doi .org/10.1111/1467-6494.0008 5

[38] Rye MS, Pargament KI, Pan W, et al. Can group interventions facilitate forgiveness of an ex-spouse? A randomized clinical trial. Journal of Consulting and Clinical Psychology. 2005; 73(5): 880-892. http://doi.org/10.1037/0022-006X.73.5.880 